Portland State University

PDXScholar

8-17-2020

\title{
Computed Tomography in Medicolegal Death Investigation: a Critical Review
}

Trenton Eames

Portland State University

Follow this and additional works at: https://pdxscholar.library.pdx.edu/honorstheses

Part of the Forensic Science and Technology Commons, and the Other Anthropology Commons Let us know how access to this document benefits you.

\section{Recommended Citation}

Eames, Trenton, "Computed Tomography in Medicolegal Death Investigation: a Critical Review" (2020). University Honors Theses. Paper 928.

https://doi.org/10.15760/honors.951

This Thesis is brought to you for free and open access. It has been accepted for inclusion in University Honors Theses by an authorized administrator of PDXScholar. Please contact us if we can make this document more accessible: pdxscholar@pdx.edu. 
Computed Tomography in Medicolegal Death Investigation: A Critical Review

by

Trenton Eames

An undergraduate honors thesis submitted in partial fulfillment of the requirements for the degree of

Bachelor of Science

in

University Honors

and

Anthropology

Thesis Adviser

Virginia Butler, Ph.D

Portland State University

2020 


\section{Introduction}

Medicolegal death investigation, or forensic death investigation, is the systematic investigation of unexplained or violent human deaths. Practitioners of this type of investigation include medical examiners, who are doctors of medicine who utilize forensic pathological study to find a corpse's identity, cause of death, or anything else out of the ordinary (1). Forensic anthropologists also partake in medicolegal death investigation, though focusing instead on remains that are heavily burned, in an advanced state of decay, or otherwise lacking soft tissue.

The field of medicolegal death investigation is one that regularly utilizes analytical methodologies and technologies from other fields. Often, practices from the field of medicine are found to be particularly applicable (2). The accuracy and precision of these new practices, defined respectively as the results' proximity to the "true" value and the proximity of the results to each other (3), must be assessed in order to ensure the resulting data are worthy of consideration in the process of death investigation. The constant pursuit of greater accuracy and precision allows for confidence in the field and the information that comes from it.

However, while the techniques and technologies adopted by the field of medicolegal death investigation are put quickly into practice, they have not always been adequately assessed for their accuracy and precision. One example of this would be forensic science's adoption of gait analysis, or the study of walking patterns. In 2000 a gait analysis "expert" was called into a courtroom to testify, thus ushering in a new investigative technique that was quickly embraced and cited in numerous court cases (4).

Even when the shortcomings of this new technique were acknowledged, the findings still had significant impact on court decisions. In 2005, footage of a bank robbery in Denmark was handed over to gait analysts. These practitioners concluded that, while the perpetrator in the 
robbery footage had a limp that was similar to a particular suspect, footage did not capture adequate gait characteristics that they required for suspect identification. Regardless of this finding, the court used this statement to make a guilty verdict (4).

In 2011 gait analysis was found to be unreliable (4). The high variability in gait analysis results meant severely low precision, and thus data that should not be used in court. In recent years, recent gait analysis research has involved ensuring precision using groups of diverse experts (4).

Computed tomographic (CT) scanning is another prime example of promising forensic technology adapted from medicine. CT scanning is the outer and internal image of a subject via X-rays. With 3D-CT scans, these images can be layered together to produce a three-dimensional rendering of the scanned subject (5). This technology is frequently used in forensic pathology and anthropology, as these scans allow investigators to learn about the deceased with minimal disturbance of the body. CT scans are frequently used to find the geometric shape and measurements of traumatic pathologies, often in an effort to identify details about the weapon used, as well as the number of strikes or impacts. CT scans also allow investigators to gather particular markers that allow for the identification of a body. As such, the information that CT scans reveal are especially helpful in cases where the deceased is in advanced stages of decomposition, or has sustained burns or other severe trauma. CT scans are also frequently utilized instead of autopsies in other countries, as well. In Japan, for example, there is a combination of minimal access to medical examiner systems and a high concentration of CT and MRI technology present within the country that lead to an increased reliance on CT for death investigation (6). Globally, there are a number of religious and cultural groups that may also hold beliefs that are against the practicing of autopsies, such as Orthodox Jews and Muslims (7). 
The importance of this work is clear - providing objective findings to questions of justice, bereavement, and public health is the ultimate goal of these death investigations. The results of these investigations affect countless lives, including family members of the decedent, criminal suspects, and the general population. The techniques used within medicolegal death investigation must be analyzed systematically and objectively to ensure that the field is doing the absolute best work it can - especially considering the hugely important nature of the findings. Utmost precision and accuracy must be pursued consistently and continually.

The goal of this research is to observe and interpret general trends within the research surrounding CT in medicolegal death investigation, creating an outline of the general views of researchers. A systematic literature review will provide a meta-analysis of existing literature surrounding the use of CT scans in the field of medicolegal death investigation. In particular, this meta-analysis focuses on the topics of postmortem CT precision, accuracy, and role within medicolegal death investigation.

\section{Background}

In order to gauge the overall position of CT within the field of medicolegal death investigation today, the conclusions of multiple works of research must be compared and considered together. Such meta-analyses are useful in their ability to provide overviews of research and discourse, creating a cohesive, generalized narrative surrounding what can be a wide variety of results and opinions. This particular meta-analysis will provide an overview of the current state of CT in forensics as well as possible areas of weakness, further research, and expert opinions on the future of using CT in death investigation. 


\section{$\underline{\text { Meta-analysis }}$}

A meta-analysis is an analysis of the combined results of multiple research studies. Meta-

analyses allow researchers to find general conclusions to be drawn from a body of research. This is a particularly useful tool for gauging aa variety of study methods and conclusions, as the combined results can provide averages that reflect those of the field overall. Meta-analyses also provide insight into the field and research discourse itself, allowing researchers to possibly identify common practices or biases affecting the research (8).

For example, in 2009 Kuhns et al. (9) performed a meta-analysis, examining research papers on the topic of narcotic toxicology findings among homicide victims. This meta-analysis combined the findings of 18 independent research studies, allowing them to specifically analyze marijuana, cocaine, and opiate toxicology among victims. Using statistical analysis of the results of these studies, Kuhns et al. found notable trends, such as a correlation between cocaine usage and homicide by firearm, as well as correlations between races and specific drugs.

My meta-analysis of research on CT in medicolegal death investigation will be largely qualitative with the addition of some statistical analysis.

\section{Taphonomy}

Paleontology is the study of life on earth through the fossil record. Taphonomy, specifically, is a branch of paleontology that is the study of the decay and fossilization of organisms. This field creates a record of the past using nothing but what physical evidence remains in the present day. Out of necessity, paleontology and taphonomy have developed a method for establishing cause and effect relationships in these contexts that cannot be tested directly. For example, Peresani et al. (10) performed taphonomic analysis on faunal remains from Fumane Cave in Italy, finding evidence in scrape marks on bird bones that indicate the 
possible use of symbols among Neandertals; marks that were consistent with feather removal were found on the skeletal remains of birds that were not known to be food sources indicated possible use of feathers ornamentally.

Dirkmaat and Cabo (11) discuss this intersection of medicolegal death investigation with forensic archaeology and taphonomy. They conclude that taphonomy's scientific approach to estimating postmortem intervals, as well as the analysis of signs of manipulation of remains, provide a framework for medicolegal death investigation to follow.

R. Lee Lyman discusses the idea of "uniformitarianism," or the combination of testable theory and procedure, as it is practiced within the field of taphonomy (12). Originally describing the uniform nature of earth's processes within the context of geology (13) "uniformitarianism" is the idea that natural processes are able to be recreated. In the context of taphonomy, this means that there are observable, reproducible patterns that allow researchers to understand the past using what physical evidence remains.

Uniformitarianism applies in much of the same way to medicolegal death investigation. Investigators must rely on physical evidence alone to reveal as much as they can of the past. The scientific basis of this field relies on the idea of uniformitarianism - natural processes are largely consistent, and as such, they can be studied and learned in an effort to recreate the past.

\section{Precision vs. Accuracy}

While often used interchangeably, for the purposes of this meta-analysis, a distinction between precision and accuracy will be used; precision will refer to how "close" results are to one another. For example, if a particular study is repeated a number of times, a low variability in results would indicate a high level of precision. Accuracy will refer to how close results are to an 
objective "truth" (14). An example of high accuracy would mean that the average results from a particular sample would be very close to the true average of a population.

I wished to know the extent to which these concepts are considered within the context of CT in medicolegal death investigation; a goal of this research was to determine whether current research focused primarily on result variability, accuracy, or some combination of the two. Precision will be assessed by how close repeated study results are to one another. The accuracy of said results, on the other hand, will be assessed by their proximity to the "true" values. It should be noted that due to the very nature of medicolegal death investigation dealing with unknown events, the truth can very rarely be known. For the purposes of this meta-analysis, autopsy results will be considered to be "true."

\section{Trauma in Medicolegal Death Investigation}

When a person dies under violent or mysterious circumstances, or if they are otherwise unidentified, they will likely fall under the jurisdiction of a medicolegal death investigation. Depending on the exact context of this investigation, it will generally involve investigators seeking a cause of death, manner of death, or aiding in the identification of the decedent. (15)

Often, these investigations involve trauma - otherwise known as physical injury. Trauma is generally divided into different types: blunt force, sharp force, ballistic, explosive, and burn. Each of these types of trauma leave distinct signs, or pathologies, on the corpse of a victim. These pathologies can appear both in skeletal and soft-tissue (muscles, organs, blood vessels, etc.) (16). The exact nature of this trauma is of extreme relevance to a death investigation, as it may provide answers to family member or even lead to a criminal conviction. 


\section{CT Scans}

A CT scan (17) is a combination of X-rays, each taken from a different angle. CT scans allow radiologists to examine areas of the body cross-sectionally - a particularly useful method for learning about internal pathologies. Since the inception of the CT scan machine in 1967, the technology has come a long way (15). Scanners range in the number of "slices," or images taken on each rotation of the arm within the machine (18). Dental cone beam CT scans involve the use of X-rays beamed in the shape of a cone, with the greater scan area allowing for the rapid collection of images that allow for the creation of a 3D image $(19,20)$. Almost all CT scan machines are expensive, with some sources suggesting that a small, refurbished scanner would cost upwards of $\$ 80,000(21,22)$.

Traditionally, in medicolegal death investigation, to understand what is happening inside a corpse, a medical examiner or coroner would have to perform an autopsy - a form of surgery in which the body is opened up and examined. However, CT scans would theoretically allow the investigator to visualize the internal pathologies of a corpse without the need to perform an autopsy. One goal of my study was to establish the extent the field supports using CT scans instead of performing autopsies.

There is a substantial amount of literature surrounding the use of CT scans in medicine, such as their role in pediatric medicine (23). There is also a substantial body of work surrounding critical review of other forensic investigation techniques, such as the analysis of literature focusing on fingerprint detection on metallic surfaces (24). Both of these types of research were reviewed to contextualize the current state of CT scans in medicolegal death investigation. 


\section{Methods}

This research is a critical analysis of literature on CT within medicolegal death investigation, with the specific purpose of assessing the focuses, methodology, and conclusions of current research. This data will be useful in guiding future research and establishing reasonable expectations of CT scan precision and accuracy within forensic contexts.

Using key words such as "CT," "medicolegal," "forensic," "post-mortem," and "computed tomography," I used online data bases such as the Portland State University Library website and Google Scholar to find peer-reviewed research papers relevant to the use of CT in medicolegal death investigation or the identification of previously unidentified corpses. A total of 36 research papers were collected, ranging in publication year from 1995 to 2020 (Appendix 1). The majority of these research papers were pulled from two leading professional journals in the field: the Journal of Forensic Sciences and Forensic Science International. All collected papers were saved as PDF files to allow for reference.

An Excel spreadsheet (Appendix 2) was created to allow for the systematic recording and categorization of the research methodology, findings, and discussion of each collected research paper. A pivot table was created from this spreadsheet that allowed for the numerical comparisons of various data fields, as well as the creation of graphics that displayed the general trends in research discussed. 
These research papers were then analyzed for their methods and conclusions, with a

specific focus on common attributes (Table 1).

Table 1-Attributes, questions the research is trying to answer, and categories for grouping answers.

\begin{tabular}{|c|c|c|}
\hline Attribute & Questions & Categories \\
\hline Sample size & What was the researchers' sample size? & $\begin{array}{l}\text { "1 -10," "11 - 100," "101 - } \\
500, " \text { "500+" }\end{array}$ \\
\hline Statistics & Was statistical analysis used? & "Yes," "No" \\
\hline CT vs. autopsy & Was CT compared to autopsy? & "Yes," "No" \\
\hline $\begin{array}{l}\text { Technology } \\
\text { comparison }\end{array}$ & $\begin{array}{l}\text { Was CT compared to other forms of } \\
\text { technology? }\end{array}$ & "Yes," "No" \\
\hline Role & $\begin{array}{l}\text { Did the researchers consider CT to be a } \\
\text { standalone technique? If so, was that } \\
\text { universal or under limited circumstances? }\end{array}$ & $\begin{array}{l}\text { "Standalone," "Limited," "Not } \\
\text { standalone" }\end{array}$ \\
\hline Approval & $\begin{array}{l}\text { Was the use of CT in medicolegal death } \\
\text { investigation approved by the researchers? } \\
\text { If so, was that under all or limited } \\
\text { circumstances? }\end{array}$ & $\begin{array}{l}\text { "Supported," "Limited w/ } \\
\text { conditions," "Not supported" }\end{array}$ \\
\hline Purpose of CT & $\begin{array}{l}\text { What was the reason for taking the CT } \\
\text { scans analyzed? }\end{array}$ & $\begin{array}{l}\text { "Detail," "Causation," } \\
\text { "Identification," "Treatment" }\end{array}$ \\
\hline Injury type & $\begin{array}{l}\text { What injury type was focused on by the } \\
\text { researchers? }\end{array}$ & $\begin{array}{l}\text { "Gunshot wound," "Blunt } \\
\text { force trauma," } \\
\text { "Strangulation," } \\
\text { "Hemorrhaging," "Not } \\
\text { specified" }\end{array}$ \\
\hline $\begin{array}{l}\text { Anatomical } \\
\text { region }\end{array}$ & $\begin{array}{l}\text { What region of the body was the CT } \\
\text { research focused on? }\end{array}$ & $\begin{array}{l}\text { "Head," "Teeth," "Neck," } \\
\text { "Torso," "Not specified" }\end{array}$ \\
\hline Accuracy & $\begin{array}{l}\text { Does the research paper focus on the } \\
\text { accuracy of CT? }\end{array}$ & "Yes," "No" \\
\hline Precision & $\begin{array}{l}\text { Does the research paper focus on the } \\
\text { precision of CT? }\end{array}$ & "Yes," "No" \\
\hline
\end{tabular}

\section{Results}

Of the 36 research papers collected, $97 \%$ were focused on assessing the accuracy of CT in medicolegal contexts. Precision, as previously defined, was determined to only be discussed directly in $64 \%$ of the papers. 
Of the 36 research papers included in this research, 21 specifically compared CT scan results to autopsy findings. The majority of these comparisons involved the use of autopsy findings as the "gold standard," or the findings closest to the objective truth of the subjects at hand. Assuming that autopsies almost always provide results closest to the "truth" of what happened to the deceased - or in the case of identification - what the true measurements and identifiable markers are, these studies comparing $\mathrm{CT}$ and autopsy results are attempting to determine the accuracy of CT scans in medicolegal death investigation contexts.

Additionally, seven of the 36 included papers had a significant focus on either comparing CT technology to other imaging techniques, or in the case of Murphy et al. (25), comparing cone-beam CT scanning to more traditional CT scanning. These comparisons lend themselves to analyzing the precision, or consistency in observations and findings, between technologies. Roberts et al. (26) compared CT imaging to MRI, finding CT to be more accurate than MRI when using autopsy results as the "true" findings; CT scans had better spatial resolution. Yen et al. (27) found CT and MRI to function similarly in their ability to detect strangulation related pathologies, though suggested that CT was slightly inferior to MRI in soft tissue hemorrhage detection. 
As seen in Figure 1, 22 research papers focused on specific regions of the body, while the remaining 14 papers considered CT scans that covered any or all parts of the body (notated as "Not specified"). The majority of these papers focused on the head, often specifically examining cranial pathologies, such as Chawla et al. (28), who compared antemortem CT scans to autopsy findings in their respective abilities to identify the presence of cranial fractures. One research paper examined the differences between using cone-beam CT scanning and traditional CT scanning on teeth to find the identity of individuals (25).

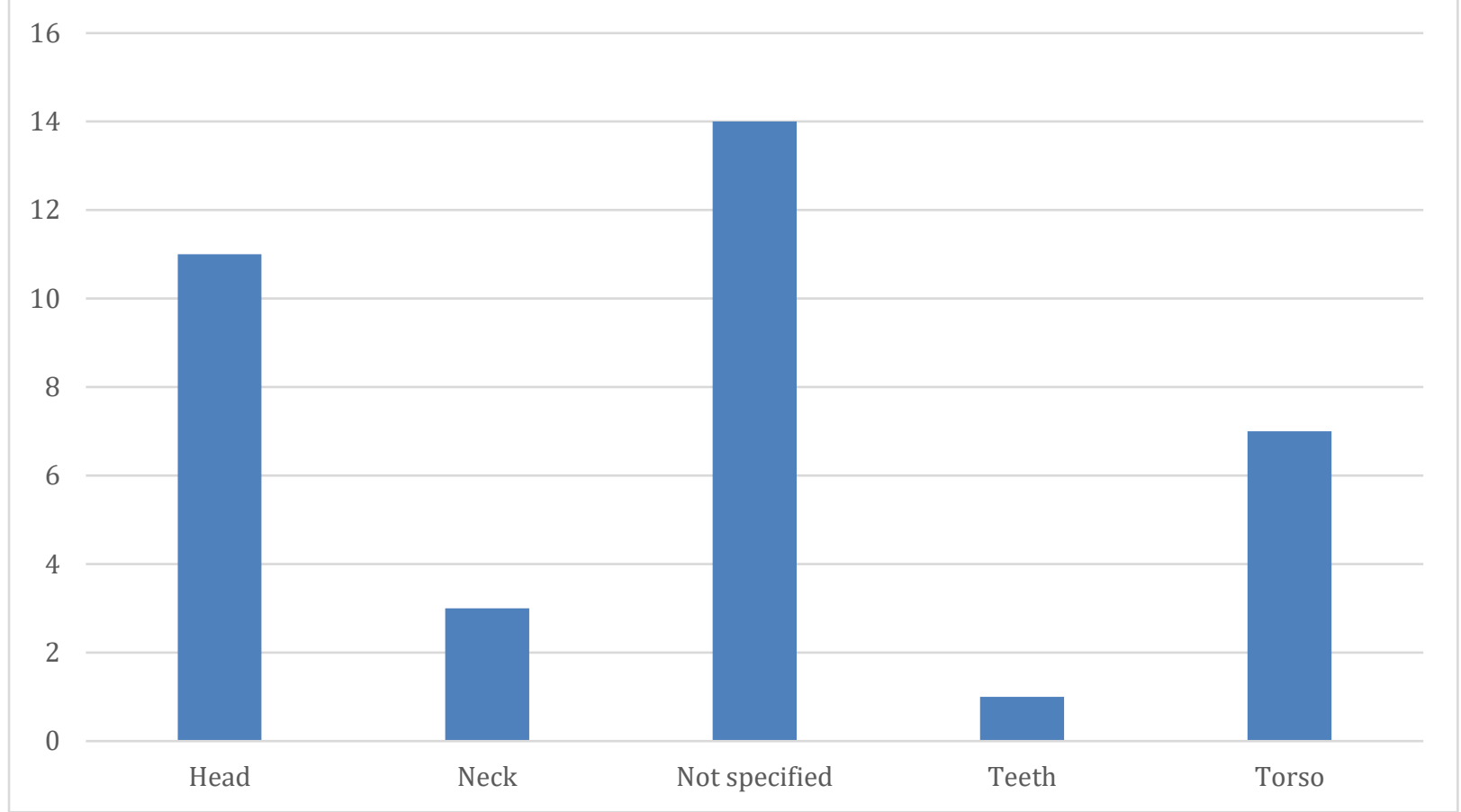

FIG. 1-Frequency of studies by specific anatomical regions. 
As seen in Figure 2, of the 30 research papers focusing on searching for pathologies, 19 focused on specific pathologies, while 13 involved scans looking for any relevant injury or illness. Of the specified pathologies, gunshots wounds were the most common focus. Giffen et al. (29) provide two case studies focusing on gunshot wounds to the head in which discrepancies exist between CT scan and autopsy results, arguing that these discrepancies resulted from a lack of CT imagining experience on the part of the image interpreter.

Following closely behind those that focus on gunshot wounds are research papers with a focus on blunt force trauma. One such example would be Grassberger et al. (30), who provide a case study of two cases of CT scans of survivors of blunt force trauma to the head, concluding that the ability to use CT scans to reconstruct 3D images of the victims allowed investigators to learn more about the particular weapon attacks in question.

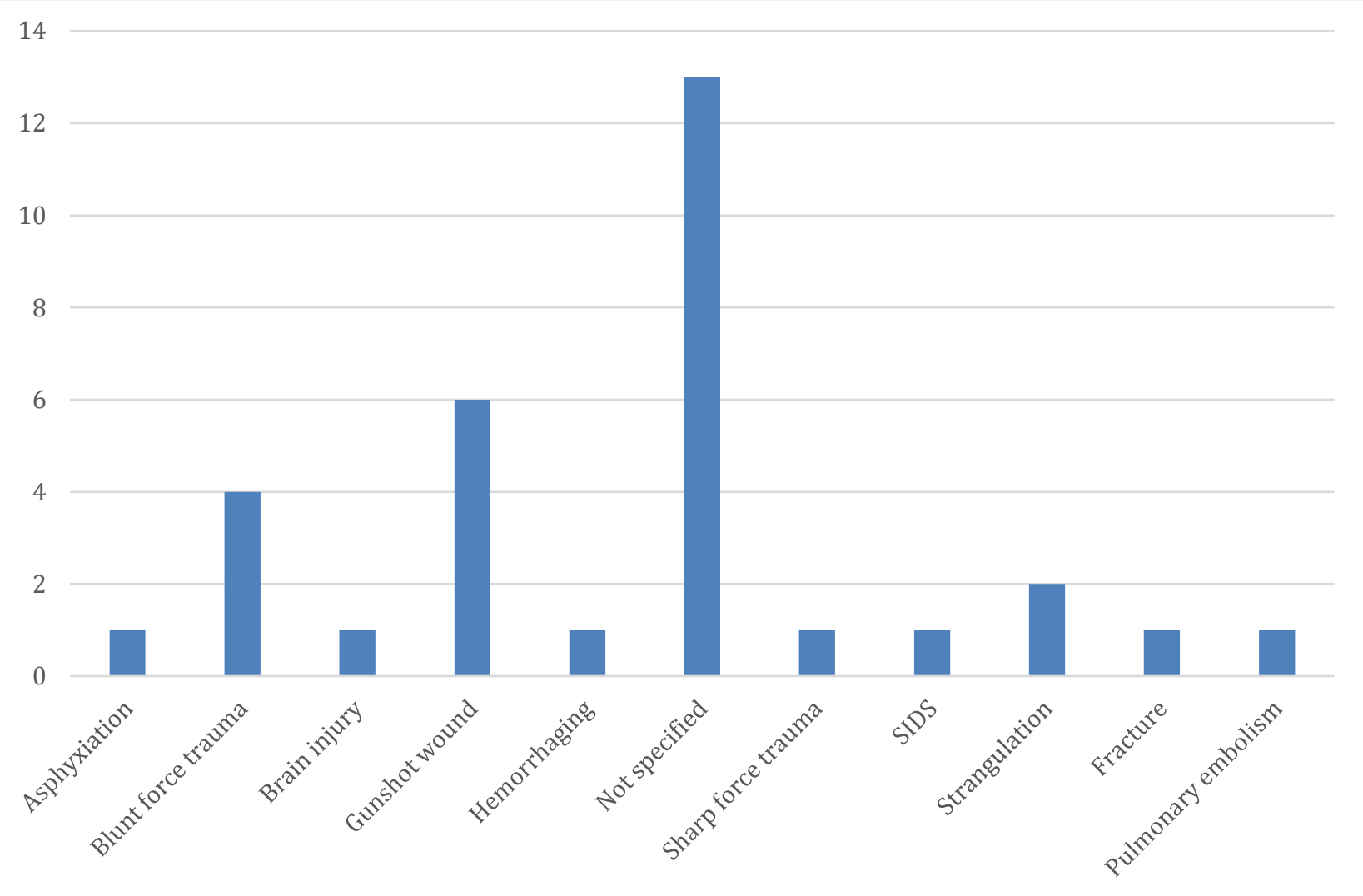

FIG. 2-Frequency of injury types focused on in research. 
Out of 35 applicable research papers, 14 had sample sizes between 11 and 100, followed closely by the range of $1-10$ samples. Those papers with fewer samples were more often case studies, allowing the researchers to cover broad aspects of CT scans in medicolegal death investigation contexts by doing a close examination of specific usage. For example, Filograna et al. (31) use a single case study to examine common errors in CT scan analysis, focusing primarily on use error and the pervasive nature of search satisfaction. Conversely, those studies with larger sample size often provide statistical analysis of specific types of error/accuracy. Poulson and Simonsen (32) compared autopsy findings with CT scan results for 525 cases, specifically exploring the utility of CT scans when analyzed by a forensic pathologist lacking radiology training. They used their large data set to look at statistical discrepancies between CT and autopsy findings, ultimately finding that CT scans proved to be useful as a supplement to autopsy, though they could be greatly improved with radiological training and a common scanning protocol.

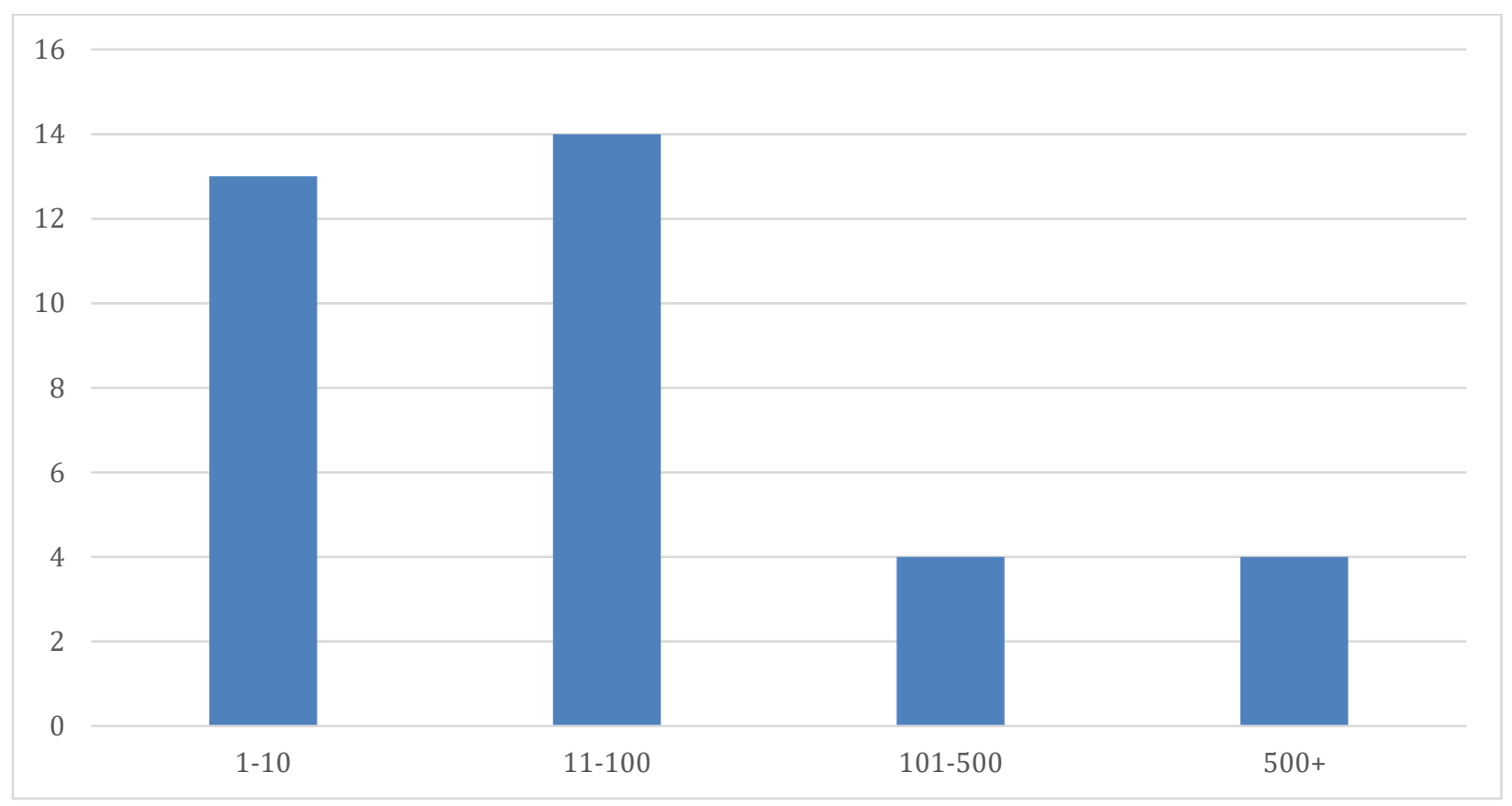

FIG. 3-Frequency of samples used in each study, categorized into groups. 
Regarding the specific intent behind taking CT scans (Figure 4), the majority of these scans were done in an effort to better understand a specific wound or illness (listed as "Detail"). Peschel et al. (33) examined the possibility of using CT scans to virtually reconstruct the skulls of gunshot wound victims in an effort to trace the bullet path. Another paper, focusing on forensic cases involving surviving victims of assault, included CT scans taken with the intent of assessing treatment plans for the survivors (34).

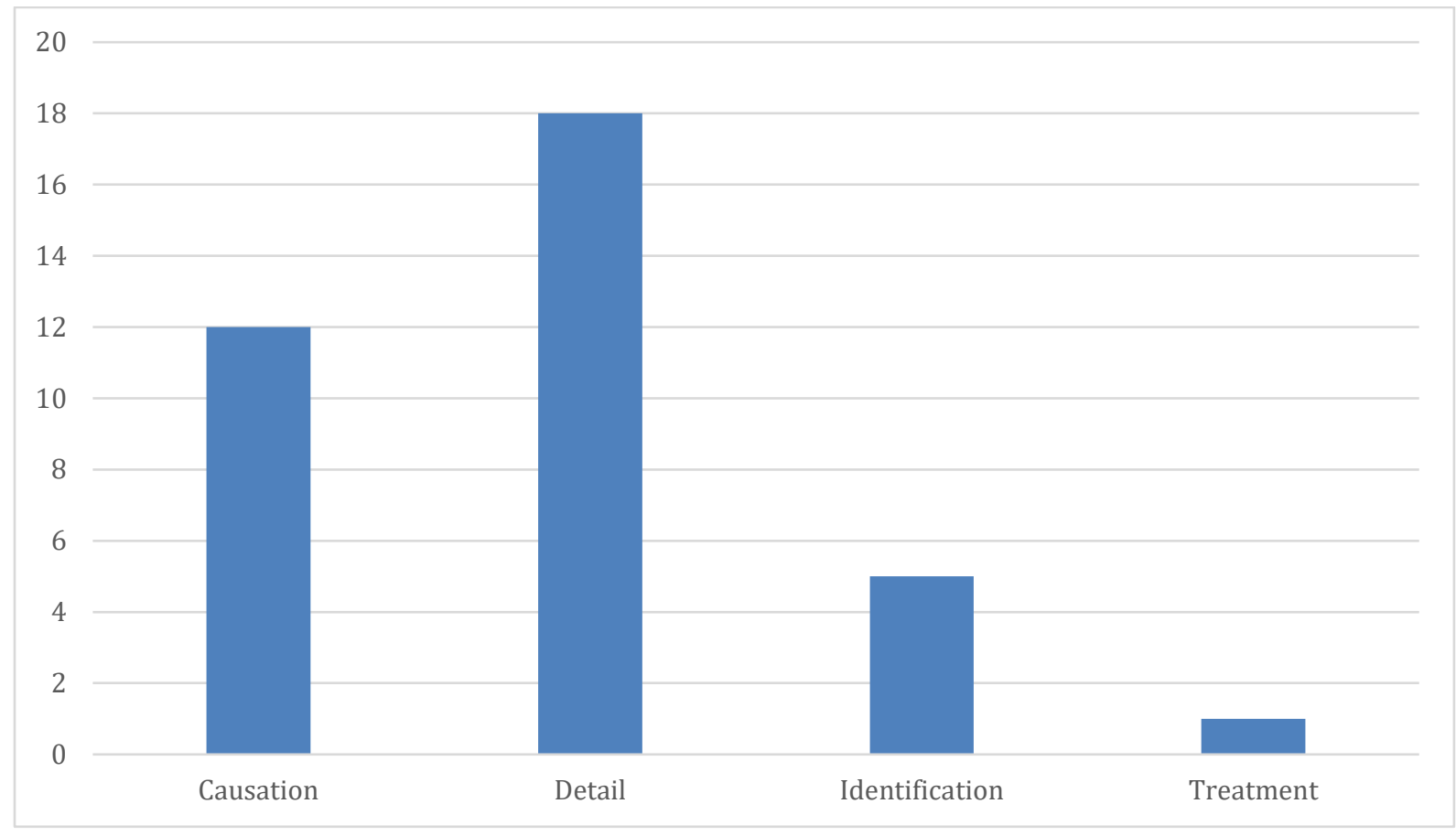

FIG. 4-Frequency of purposes of CT scans. 
As seen in Figure 5, 25 of the research papers suggested that the use of this technology would be appropriate under limited circumstances, such as if paired with required training for the analyst or an improvement in CT scan resolution. Grasseberger et al. (30) suggest that CT scans provide useful information, but should only be analyzed by forensic pathologists with radiological experience. Nine of the papers suggested outright approval of CT scans in forensics, while one suggested that CT scans provided little value when compared to autopsy.

Figure 6 places these approval results over time, showing a progression in the research since the earliest publication in 1995. When examining the approval over time, we see an increase in support of CT usage. Filograna et al., in 2010, cite radiologist error as a significant problem in the use of postmortem CT scans (31). By contrast, in 2018, Decker et al. found that there was no significant difference between CT scan and autopsy results (35).

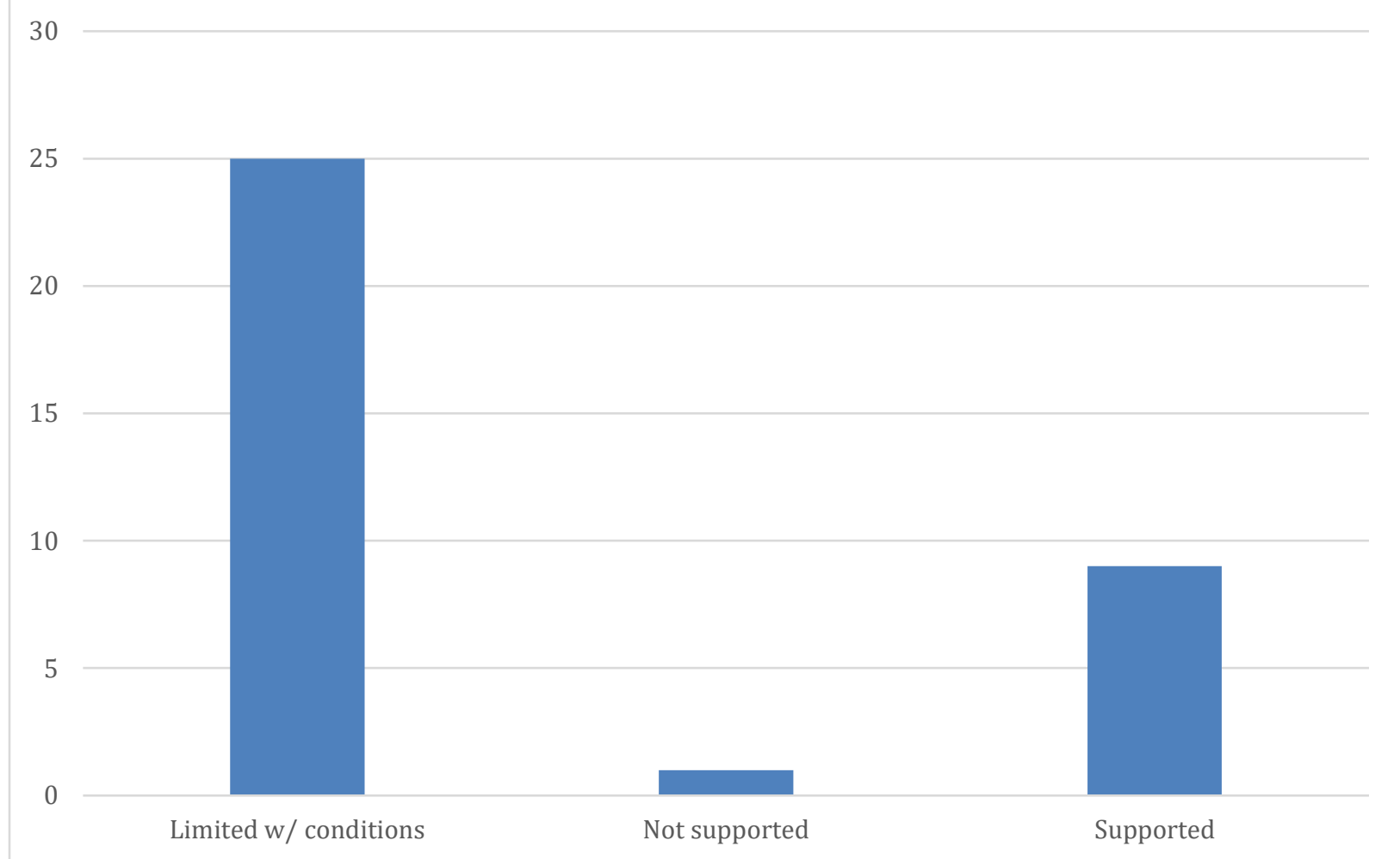

FIG. 5-Frequency of researcher support of CT in medicolegal death investigation based on general grouping. 


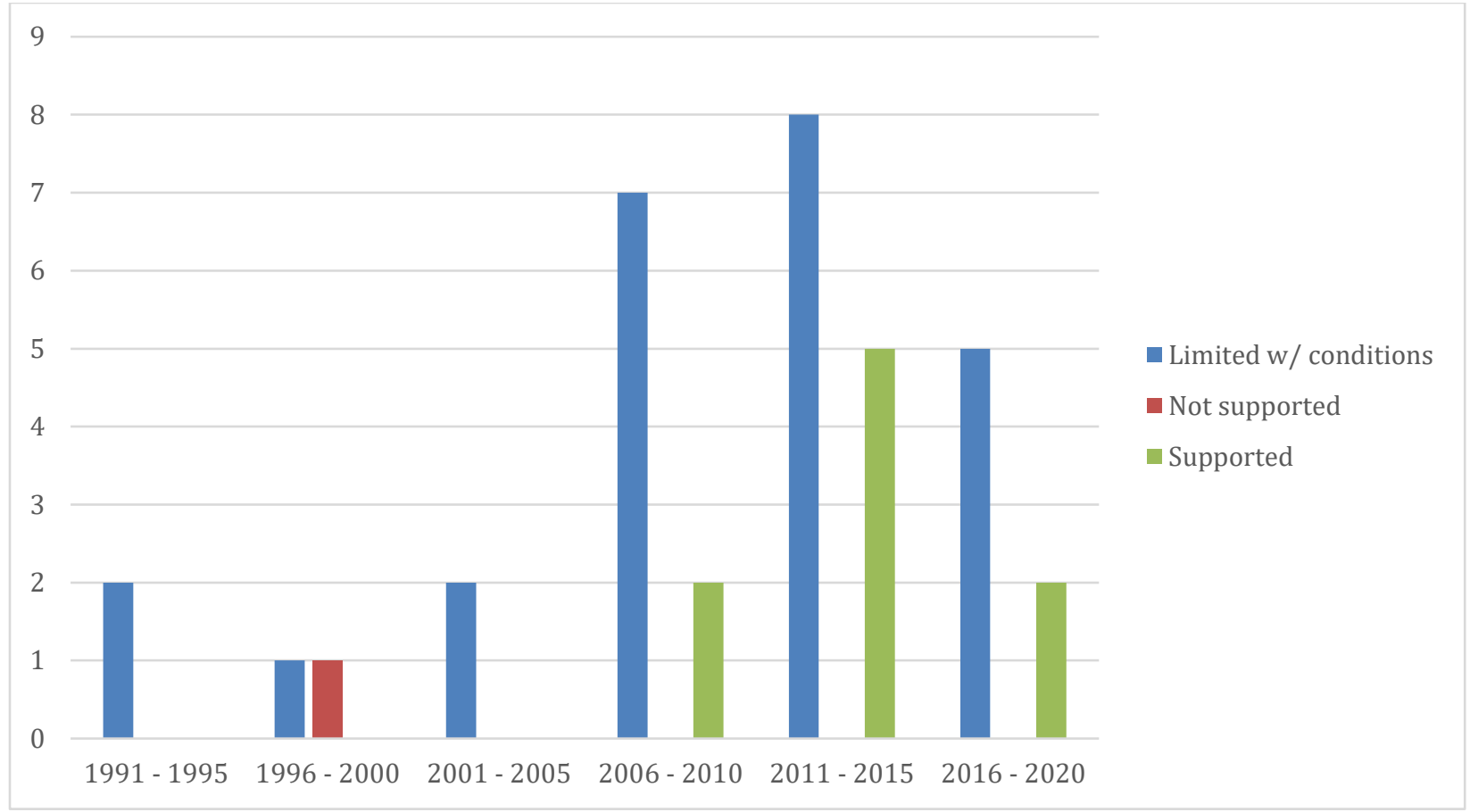

FIG. 6-The total approval classifications of the analyzed research over time. 
Additionally, as seen in Figure 7, researchers tended to discuss the usage of CT scans within the context of other techniques such as autopsy or other imaging techniques. The research papers were divided into those that approved of $\mathrm{CT}$ as a standalone technique, a standalone technique under certain circumstances (such as limited ability to do autopsy), or a technique that should not be solely relied on under any circumstance. One such research paper suggesting CT not be a standalone technique was published by Delteil et al. (36), stating that due to the difficulty in interpreting CT scans (especially surrounding gunshot wounds), CT results should always be compared to autopsy findings.

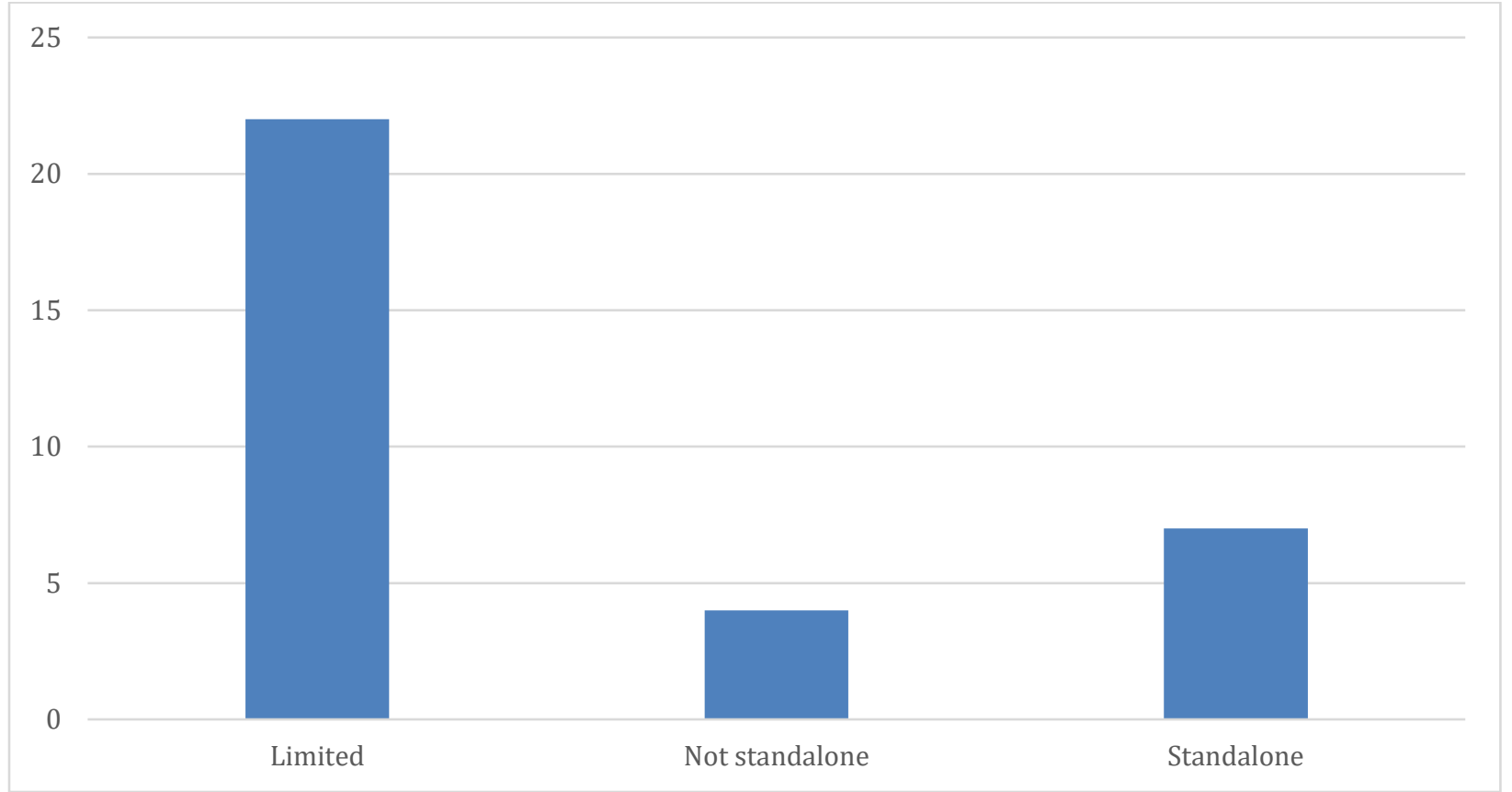

FIG. 7-Researcher view on independence of CT scans as a medicolegal investigative technique.

\section{Discussion}

The majority of the literature reviewed used autopsy findings as the "gold standard," against which they compared the findings of post-mortem CT scans, indicating a general interest within the existing research in analyzing the accuracy of this particular technique. There were 
some notable cases in which CT was considered to be at least slightly-more precise than autopsies in certain aspects $(37,38)$.

There were a number of discussions regarding some of the pitfalls of CT scanning, particularly regarding the occasional missed sign of soft-tissue damage $(35,38)$. There were also some trends in the discussions surrounding user error and biases - particularly in the ability of these errors to significantly affect the interpretation of these scans $(29,31)$.

Limitations of the technology were also discussed, such as poor ability to capture softtissue damage and image artifacts when scanning dental work $(38,25)$. Roberts et al. (26) also found statistical discrepancies between CT and autopsy findings, citing the frequency of missed causes of death on CT and MRI.

These specific scenarios in which CT scans can yield low accuracy are areas that future CT research should focus on exploring. These weaknesses should also be acknowledged and kept in the forefront of analysts' minds when using this technique independently from autopsy or another imaging technique. Most of the literature reviewed, however, found that there were no significant differences in the abilities of $\mathrm{CT}$ and autopsies to identify bone fractures relating to traumatic injury $(39,27)$. This indicates that CT scans might be reliable as standalone investigative technique, potentially replacing autopsy, when used for certain types of injuries.

Many of the research papers emphasized that specific post-mortem CT training should be provided to investigators who will be analyzing such images to increase precision between analysists as much as possible.

There was also a notable trend in the literature of researchers discussing the role of CT scanning within the field, suggesting it might be either a possible replacement for (37), or supplement to, autopsies $(32,40)$. The vast majority of the research included in this meta- 
analysis (22 out of 37) suggested that CT scans might be viable as a standalone investigative technique, though only under extenuating circumstances - especially those that would limit the ability to perform other tests.

The majority of the research emphasized the value of CT scans to medicolegal death investigation. Though the technology is expensive, this research indicates that coroner and medical examiner offices should try to get access to CT scanners. Additionally, many of the errors surrounding CT scans involved misinterpretation and mishandling of CT scan images; it would be in the best interest of the field of medicolegal death investigation to establish a training program for postmortem CT scan interpretation, as well as to utilize the interpretation of trained radiologists whenever possible. With the establishment of systems of training, the reliability of CT scan results will be greater.

Overall, there seems to be a growing interest in assessing both the accuracy and the precision of CT scans, though there should be a greater emphasis on the precision of these scanners going forward.

Though there is variety in the results of these research papers, the effort to ensure that this technique is worthwhile and valuable is evident. The technology is not without its pitfalls, but its immense value to the field is clear.

\section{Conclusions}

The majority of the research indicated that CT scans are viable supplements to autopsy, as well as viable replacements under certain circumstances, such as with certain injury types or when autopsy is unavailable. Certain weaknesses of CT scans were generally agreed upon 
throughout the literature, including a poor ability to pick up soft tissue damage as well as a particular vulnerability to user error.

The literature generally indicated that CT scans have great value to medicolegal death investigation. The CT scan results were described as being beneficial as supplemental data collection to autopsies, as well as possible standalone investigative tools in the event that investigators are limited in their ability to use other techniques. Coroners and medical examiner offices should prioritize gaining access to CT scanners, and the field should establish a thorough training program to allow investigators to interpret these scans with greater accuracy and precision. Additionally, radiologists should be consulted in the interpretation of CT scans, as well as in the creation of the training system.

Future research surrounding the use of CT scans in medicolegal death investigation should focus on further assessing the accuracy and precision of the investigative technique, exploring the issues surrounding the imaging of soft-tissue damage, and the possible creation and implementation of post-mortem CT scan training. 


\section{References}

1. DiMaio DJ, DiMaio VJM. Forensic pathology. New York, NY: Elsevier Science Publishing Co., Inc., 1989;1-15.

2. Dror IE, Morgan RM. A Futuristic Vision of Forensic Science. Journal of Forensic Sciences 2020;65(1):8-10. https://doi.org/10.1111/1556-4029.14240.

3. Wright DK. Accuracy vs. Precision: Understanding Potential Errors from Radiocarbon Dating on African Landscapes. Afr Archaeol Rev 2017;34(3):303-19. https://doi.org/10.1007/s10437-017-9257-z.

4. Macoveciuc I, Rando CJ, Borrion H. Forensic Gait Analysis and Recognition: Standards of Evidence Admissibility. Journal of Forensic Sciences 2019;64(5):1294-303. https://doi.org/10.1111/1556-4029.14036.

5. MacDonald D. Computed tomography. In: Oral and Maxillofacial Radiology. Hoboken, NJ: John Wiley \& Sons, Ltd, 2019;73-88. https://doi.org/10.1002/9781118786734.ch4

6. Okuda T, Shiotani S, Sakamoto N, Kobayashi T. Background and current status of postmortem imaging in Japan: Short history of "Autopsy imaging (Ai)." Forensic Science International 2013;225(1):3-8. https://doi.org/10.1016/j.forsciint.2012.03.010.

7. Ethnomed. Issues of Culture and the Role of Medical Examiner. https://ethnomed.org/resource/issues-of-culture-and-the-role-of-medical-examiner/ (accessed August 16, 2020).

8. Haidich AB. Meta-analysis in medical research. Hippokratia 2010;14(Suppl 1):29-37.

9. Kuhns JB, Wilson DB, Maguire ER, Ainsworth SA, Clodfelter TA. A meta-analysis of marijuana, cocaine and opiate toxicology study findings among homicide victims. Addiction 2009;104(7):1122-31. https://doi.org/10.1111/j.1360-0443.2009.02583.x.

10. Peresani M, Fiore I, Gala M, Romandini M, Tagliacozzo A, Trinkaus E. Late Neandertals and the intentional removal of feathers as evidenced from bird bone taphonomy at Fumane Cave 44 ky B.P., Italy. Proceedings of the National Academy of Sciences of the United States of America 2011;108(10):3888-93. https://doi.org/10.1073/pnas.1016212108

11. Dirkmaat DC, Cabo LL. Forensic Archaeology and Forensic Taphonomy: Basic Considerations on how to Properly Process and Interpret the Outdoor Forensic Scene. Acad Forensic Pathol 2016;6(3):439-54. https://doi.org/10.23907/2016.045.

12. Lyman RL. Taphonomy in Practice and Theory. In Vertebrate Taphonomy. New York, NY: Cambridge University Press, 1994;41-69.

13. National Geographic Society. Uniformitarianism. http://www.nationalgeographic.org/encyclopedia/uniformitarianism/ (accessed August 
$16,2020)$.

14. Lubinski PM, Lyman RL, Johnson MP. Blind Testing of Faunal Identification Protocols: A Case Study with North American Artiodactyl Stylohyoids. American Antiquity 2020; undefined/ed:1-14. https://doi.org/10.1017/aaq.2020.45.

15. Hanzlick R. Overview of the Medicolegal Death Investigation System in the United States. In: Institute, of Medicine, et al. Medicolegal Death Investigation System: Workshop Summary. Washington, D.C.: The National Academies Press, 2003;7-8.

16. Davidson K, Davies C, Randolph-Quinney P. Skeletal Trauma. In: Black S, Ferguson E, editors. Forensic Anthropology: 2000 to 2010. Boca Raton, FL: Taylor \& Francis Group, 2011;183-205.

17. Mayo Clinic. CT scan. https://www.mayoclinic.org/tests-procedures/ct-scan/about/pac20393675 (accessed August 16, 2020).

18. Amber Diagnostics. The Different Types of CT Scanners https://www.amberusa.com/blog/types-of-ct-scanners/ (accessed August 16, 2020).

19. FDA. Dental Cone-beam Computed Tomography. https://www.fda.gov/radiationemitting-products/medical-x-ray-imaging/dental-cone-beam-computed-tomography (accessed August 16, 2020)

20. RadiologyInfo. Dental Cone Beam CT. https://www.radiologyinfo.org/en/info.cfm?pg=dentalconect (accessed August 17, 2020).

21. Meridian Leasing. CT Scanner Buyers Guide: Slice Counts and Pricing. https://www.meridianleasing.com/blog/medical-equipment-blog/ct-scanner-buyers-guide (accessed August 17, 2020).

22. Block Imaging. How Much Does a CT Scanner Cost? https://info.blockimaging.com/how-much-does-a-ct-scanner-cost (accessed August 17, 2020).

23. Fundaro C, Caldarelli M, Monaco S, Cota F, Giorgio V, Filoni S, et al. Brain CT Scan for Pediatric Minor Accidental Head Injury. An Italian Experience and Review of Literature. Child's Nervous System 2012;28(7):1063-1068. https://doi.org/10.1007/s00381-012$\underline{1717-9}$

24. Christofidis G, Morrissey J, Birkett JW. Detection of Fingermarks-Applicability to Metallic Surfaces: A Literature Review. Journal of Forensic Sciences 2018;63(6):1616. https://doi.org/10.1111/1556-4029.13775.

25. Murphy M, Drage N, Carabott R, Adams C. Accuracy and Reliability of Cone Beam Computed Tomography of the Jaws for Comparative Forensic Identification: A 
Preliminary Study*. Journal of Forensic Sciences 2012;57(4):964-8. https://doi.org/10.1111/j.1556-4029.2012.02076.x.

26. Roberts IS, Benamore RE, Benbow EW, Lee SH, Harris JN, Jackson A, et al. Postmortem imaging as an alternative to autopsy in the diagnosis of adult deaths: a validation study. The Lancet 2012;379(9811):136-42. https://doi.org/10.1016/S01406736(11)61483-9.

27. Yen K, Thali MJ, Aghayev E, Jackowski C, Schweitzer W, Boesch C, et al. Strangulation signs: Initial correlation of MRI, MSCT, and forensic neck findings. Journal of Magnetic Resonance Imaging 2005;22(4):501-10. https://doi.org/10.1002/jmri.20396.

28. Chawla H, Yadav RK, Griwan MS, Malhotra R, Paliwal PK. Sensitivity and specificity of CT scan in revealing skull fracture in medico-legal head injury victims. Australas Med J 2015;8(7):235-8. https://doi.org/10.4066/AMJ.2015.2418.

29. Giffen MA, Powell JA, McLemore J. Forensic Radiology Pitfalls: CT Imaging in Gunshot Wounds of the Head. Journal of Forensic Sciences 2018;63(2):631-4. https://doi.org/10.1111/1556-4029.13576.

30. Grassberger M, Gehl A, Püschel K, Turk EE. 3D reconstruction of emergency cranial computed tomography scans as a tool in clinical forensic radiology after survived blunt head trauma-Report of two cases. Forensic Science International 2011;207(1):e19-23. https://doi.org/10.1016/j.forsciint.2010.11.014.

31. Filograna L, Tartaglione T, Filograna E, Cittadini F, Oliva A, Pascali VL. Computed tomography (CT) virtual autopsy and classical autopsy discrepancies: Radiologist's error or a demonstration of post-mortem multi-detector computed tomography (MDCT) limitation? Forensic Science International 2010;195(1):e13-7. https://doi.org/10.1016/j.forsciint.2009.11.001.

32. Poulsen K, Simonsen J. Computed tomography as routine in connection with medicolegal autopsies. Forensic Science International 2007;171(2):190-7. https://doi.org/10.1016/j.forsciint.2006.05.041.

33. Peschel O, Szeimies U, Vollmar C, Kirchhoff S. Postmortem 3-D reconstruction of skull gunshot injuries. Forensic Science International 2013;233(1):45-50. https://doi.org/10.1016/j.forsciint.2013.08.012.

34. Stone JA, Slone HW, Yu JS, Irsik RD, Spigos DG. Gunshot wounds of the brain: Influence of ballistics and predictors of outcome by computed tomography. Emergency Radiology 1997;4(3):140-9. https://doi.org/10.1007/BF01508103.

35. Decker LA, Hatch GM, Lathrop SL, Nolte KB. The Role of Postmortem Computed Tomography in the Evaluation of Strangulation Deaths. Journal of Forensic Sciences 
2018;63(5):1401-5. https://doi.org/10.1111/1556-4029.13760.

36. Delteil C, Gach P, Ben Nejma N, Capasso F, Perich P, Massiani P, et al. Tangential cranial ballistic impact: An illustration of the limitations of post-mortem CT scan? Legal Medicine 2018;32:61-5. https://doi.org/10.1016/j.legalmed.2018.03.004.

37. Thali MJ, Yen K, Vock P, Ozdoba C, Kneubuehl BP, Sonnenschein M, et al. Imageguided virtual autopsy findings of gunshot victims performed with multi-slice computed tomography (MSCT) and magnetic resonance imaging (MRI) and subsequent correlation between radiology and autopsy findings. Forensic Science International 2003;138(1):8. https://doi.org/10.1016/S0379-0738(03)00225-1.

38. Le Blanc-Louvry I, Thureau S, Duval C, Papin-Lefebvre F, Thiebot J, Dacher JN, et al. Post-mortem computed tomography compared to forensic autopsy findings: a French experience. Eur Radiol 2013;23(7):1829-35. https://doi.org/10.1007/s00330-013-2779$\underline{0}$.

39. Hong TS, Reyes JA, Moineddin R, Chiasson DA, Berdon WE, Babyn PS. Value of postmortem thoracic CT over radiography in imaging of pediatric rib fractures. Pediatr Radiol 2011;41(6):736-48. https://doi.org/10.1007/s00247-010-1953-7.

40. Willaume T, Farrugia A, Kieffer E-M, Charton J, Geraut A, Berthelon L, et al. The benefits and pitfalls of post-mortem computed tomography in forensic external examination: A retrospective study of 145 cases. Forensic Science International 2018;286:70-80. https://doi.org/10.1016/j.forsciint.2018.02.030. 